\title{
Direct and Indirect Relationships Between Life Satisfaction, Values, and Time Perspectives: Research on a Sample of Polish Students
}

\author{
Józef Maciuszek', Romuald Polczyk², and Kinga Tucholska \\ ' Institute of Applied Psychology, Jagiellonian University, Cracow, Poland \\ ${ }^{2}$ Institute of Psychology, Jagiellonian University, Cracow, Poland
}

\section{KEYWORDS}

life satisfaction

values

time perspectives

indirect relationships

path analysis

ABSTRACT

This study concerned the relationships among personal values (conformity, tradition, benevolence, universality, self-direction, stimulation, hedonism, achievement, power, safety), time perspectives by Zimbardo (past negative, past positive, present hedonistic, present fatalistic, future) and life satisfaction. The main hypothesis stated that value priorities would predict life satisfaction both directly and indirectly through time perspectives. 237 Polish students (120 females) took part in the study. Path analysis demonstrated that life satisfaction was directly and positively predicted by the value of benevolence, and indirectly and negatively by conformity and tradition via the past negative time perspective. Life satisfaction was also indirectly predicted by the values of hedonism and security via the future time perspective - Hedonism was a negative, and security a positive predictor of future time perspective, and the future time perspective was a positive predictor of life satisfaction. The significance of these results for mechanisms and predictors of life satisfaction is discussed.

\section{INTRODUCTION}

Values and time are important constructs in analysing human existence. Research has found that personal values and time perspective (TP) are important predictors of subjective well-being (SWB). However, these two constructs are usually analysed separately and no relationships between them were established in the context of their influence on SWB. In other research areas, there are few studies linking values and time as well (Milfont \& Gouveia, 2006).

Our study aims to address this gap. Its main goal was to analyze the complex direct and indirect relationships between values, TP, and life satisfaction (LS), which is a cognitive component of SWB. In our research, we focused on LS as the dependent variable. Values and TP served as the predictor variables, both of which are conceptualized as cognitive and motivational constructs. We assumed that the relationship between values and LS may be mediated by TP. Hence, we tested the hypothesis that, apart from a direct effect of values on LS, there is an indirect effect of values on LS through TP. Below, we give a rationale

Corresponding author: Romuald Polczyk, Institute of Applied Psychology, Jagiellonian University, Ingardena 6, 30-060 Cracow, Poland.

e-mail: romuald.polczyk@uj.edu.pl 
for this mediational hypothesis. We will briefly introduce the variables of interest, paying particular attention to their cognitive and motivational aspects. Next, we will discuss previous research concerning the relationship between values, TP, and LS. Then, we will present the idea of our research, hypotheses, and their discussion.

\section{Relation of Values, Time Perspective, and Life Satisfaction-A Cognitive Framework}

\section{THE ATTENTION, INTERPRETATION, AND MEMORY MODEL AND THE COGNITIVE ASPECT OF SUBJECTIVE WELL-BEING}

Values, TP, and LS may be analyzed from the perspective of cognitive processes. In our mediational model, TP is a mediator of the impact of values on LS. Life satisfaction is, in turn, viewed as the cognitive component of SWB. We assume that at the base of LS lie three cognitive processes, described by Diener and Biswas-Diener (2008) in the attention, interpretation, and memory (AIM) model. Firstly, according to AIM, SWB depends primarily on the object of attention, the degree of focus on successes and fortunate circumstances, and the degree of savoring the present moment. Secondly, SWB is related to positive cognitive strategies, particularly positive interpretations and reinterpretations of events. These build one's hope for a better future and protect or strengthen positive self-esteem. Thirdly, SWB is influenced by the content of recollections and the way in which past experiences are reconstructed.

\section{VALUES AND TIME PERSPECTIVE IN THE CONTEXT OF SUBJECTIVE WELL-BEING}

Schwartz (2012) recognizes values as cognitive representations (beliefs) of desired trans-situational goals. People's values form an ordered system of priorities that differ by importance and serve as standards guiding actions and judgments. Schwartz identifies ten basic personal values: conformity, tradition, benevolence, universalism, self-direction, hedonism, achievement, power, security, and stimulation (for a detailed description see Schwartz, 2012). As Sagiv and Schwartz (2000) note, "the crucial content aspect that distinguishes among values is the type of motivational goal they express" (p. 178). Values are included in the context of human well-being. Sagiv and Schwartz (2000) describe two aspects of the search for relationships between basic values and SWB. The first concerns the value profiles that facilitate SWB, while the second concerns an individual's potential to express and implement personally important values. It would seem that the link between values and SWB has been most often explored in terms of an emotional and cognitive assessment of one's own life.

Conceptions of SWB usually take into account the important role played by time perception (Bryant, 2003; Cunningham, Zhang, \& Howell, 2015; Durayappah, 2010; Kim-Prieto, Diener, Tamir, Scollon, \& Diener, 2005; Pavot, Diener, \& Suh, 1998). The AIM model also refers to time perspective (TP), or the overall orientation to time, conceptualized as a flexible dynamic process (Zimbardo \& Boyd, 1999). This is based on the premise that TP is a cognitive-motivational phenomenon, because it originates in thoughts, while thinking about time influences specific decisions and causes commitment to specific behaviours (Mello \& Worrell, 2015).

In this respect, this approach may help to explain TP's influence on SWB. As Zhang and Howell (2011) noticed, "the cognitive processes by which individuals remember, experience, and anticipate the circumstances in their life explain important variance in life satisfaction" (p. 1261).

Researchers have distinguished five TPs (Zimbardo \& Boyd, 1999, pp. 1274-1275): past positive (a warm, sentimental, accepting attitude toward the past), past negative (a negative, aversive view of the past), present hedonistic (a hedonistic, risk-taking orientation toward pleasure with little concern for future consequences), present fatalistic (a helpless, hopeless attitude toward the future and life), and future (a general orientation toward the future, weighting the consequences of one's actions, striving for future goals and rewards). One of the key assumptions in Zimbardo's psychological theory of time (Zimbardo \& Boyd, 2008) is that one's perception of the world, lifestyle, decisions, and activities are determined by their TP.

Empirical research results indicate that both TP and values are relevant constructs for SWB. For example, there is a strong negative correlation between SWB and both the past negative (Boniwell, 2005; Boniwell, Osin, Linley, \& Ivanchenko, 2010; Drake, Duncan, Sutherland, Abernethy, \& Henry, 2008; Stolarski \& Matthews, 2016; Zhang \& Howell, 2011; Zhang, Howell, \& Stolarski, 2013) and the present fatalistic (Boniwell, 2005; Zhang \& Howell, 2011; Zhang et al., 2013) TP. In contrast, SWB is positively correlated with both the past positive and the present hedonistic TP (Boniwell, 2005; Boniwell et al., 2010; Drake et al., 2008; Dwivedi \& Rastogi, 2017; Zhang et al., 2013).

The association between SWB and the future TP is unclear. Some studies found a positive correlation (Anagnostopoulos \& Griva, 2012; Boniwell, 2005; Dwivedi \& Rastogi, 2017; Zhang \& Howell, 2011), while another did not (Drake et al., 2008).

Results on the relationship between values and SWB are even less consistent. Based on the Schwartz (2006) model of values, they confirm associations between value priorities and SWB, particularly affective well-being (Sagiv \& Schwartz, 2000). However, Sagiv and Schwartz (2000) did not find any associations between values and the cognitive aspect of well-being. Similar results were reported by other studies (Roccas, Sagiv, Schwartz, \& Knafo, 2002). Nevertheless, some studies have found significant correlations between values and LS. For example, Özdemir (2014) showed that LS correlated positively with tradition and negatively with universalism in a group of Turkish adults. Tayli (2015) showed that only self-direction and stimulation values did not correlate with LS in a group of Turkish college students. Haslam, Whelan, and Bastian (2009) also found that LS was positively correlated only with stimulation.

To sum up, results of previous studies demonstrated a correlation between SWB and both personal value priorities and TP. However, as was already mentioned, few studies explored the relationships between 
all these three constructs. For example, there is some research where $\mathrm{TP}$ and values have been proven to be related and constitute additional predictors of other variables, for example, environmental attitudes (Milfont \& Gouveia, 2006).

\section{The Present Study: The Mediating Role of Time Perspective}

What theoretical claims support the assumption about the mediating role of TP for other variables? It is commonly assumed that TP is related to personality (Fortunato \& Furey, 2009; Zhang \& Howell, 2011), including the Big Five traits (Dunkel \& Weber, 2010; Kairys \& Liniauskaite, 2015). It is therefore possible that values, which are an important part of personality (apart from traits), influence the way individuals perceive time and reflect on life circumstances and events.

According to Schwartz (2006), values, which are a motivational construct, refer to desirable goals and serve as guidance in evaluating actions and events. Therefore, values may influence the way people experience and manage time. For example, depending on our goals, one might be oriented towards a closer or more distant future, as goals also influence experience of the present (Cantor \& Zirkel, 1990). As criteria for judgement, values may also cause a person to perceive the past more negatively or positively (past positive and past negative TPs). As was discussed above, there is research showing the link between some values and LS, as well as between TP and LS. We believe that some values may influence LS indirectly, via TP. For example, if an individual has a high achievement value, they may be more oriented towards the future TP. Present hedonistic TP may be important for stimulation and hedonism values. For conformity and tradition, the past positive TP seems most relevant. As these TPs are linked to LS (as discussed above), in all of these cases values would be related indirectly to LS via TP. Also, in some existing research, TPs were analyzed as a mediator of the impact of predictors on SWB, such as personality traits (Haslam et al., 2009), neuroticism (Sobol-Kwapinska, 2016), or mindfulness (Stolarski, Vowinckel, Jankowski, \& Zajenkowski, 2016).

Why was a model with a reverse mediation not assumed? We assumed that values can indirectly influence LS via TP. It is less probable that TP influences LS via values. Both values and TPs are shaped by socio-cultural influences, but the former are more primary and stable. They may even be inherited to some extent (Uzefovsky, Döring, \& Knafo-Noam, 2016). On the other hand, TPs are dynamic processes, influenced by environment and culture, and it is possible to change them by means of psychological influence, that is, time perspective therapy (Sword, Sword, Brunskill, \& Zimbardo, 2014) or time perspective coaching (Boniwell, Osin, \& Sircova, 2014). Time perception may also modify goals. Carstensen, Isaacowitz and Charles (1999) note that perception of time is malleable and plays a fundamental role in the selection and pursuit of social goals.

Existing research on the relationships between values and SWB yielded mixed results, which makes it somewhat difficult to make precise predictions. This inconsistency may be due to a number of factors. First, there are various perspectives that can be applied, such as the healthy values perspective, the goal-attainment perspective, and the value congruency perspective (see Sagiv, Roccas, \& Hazan, 2004). Secondly, SWB may be more readily influenced by the implementation or defence of a person's values rather than by their profile of value priorities. Thirdly, there are various moderators of the association between values and SWB, such as cultural differences and the Human Development Index. Some studies have found that a country's level of socio-economic development moderated the relationship between values and LS (Sortheix \& Lönnqvist, 2014). Fourthly, this association can be mediated by several factors, that is, there may be various mechanisms underlying the relationship between values and SWB. For example, studies by Haslam et al. (2009) found that the association between values and SWB was mediated by the Big-Five personality traits. Sagiv and Schwartz (2000) investigated not only direct relations between values and SWB, but also whether SWB depends on the congruence between values and the prevailing value environment.

\section{HYPOTHESES IN THE PRESENT STUDY}

We expected an indirect effect of values on LS through TP. This hypothesis was based on speculations linking at least some values to TPs, and TPs to LS. We postulate that achievement is positively connected with future (see Lu, Li, Fung, Rothermund, \& Lang, 2018), as future means striving for forthcoming, not yet present, goals and achievements. Tradition may be related to both past positive and past negative TP (Zimbardo and Boyd, 2008). Obviously, stimulation and hedonism should be positively related to present hedonistic. We also expected self-direction to be negatively related to present fatalistic: if one values controlling one's life, they would not think that the reality is fatalistic and uncontrollable. Moreover, power and safety may be positively related to future, as hoping for good future times assumes at least some basic level of perceived controllability and safety.

As for the second part of the mediation hypothesis, we postulated that TPs will relate to LS. Past negative TP means that a person has an aversive view of the past; this was expected to have a negative impact on current LS because negative beliefs about the past may generalize to the present. Accordingly, past positive, reflecting an accepting attitude toward the past, should have a positive impact on present life satisfaction, as should present hedonistic. A future TP means that one is motivated towards achieving goals. We expected it to be positively correlated with LS.

The above considerations concerned the indirect effects of values on LS via TPs. Apart from that, we also expected at least some values to be directly connected to LS. Benevolence should have a positive impact on LS, as it is a value which implies less aggression and negative emotions, possibly promoting LS. Hedonism should also be positively related to LS, as well as to universality, as it implies a positive orientation towards humanity, which, in general, should result in a lower general amount of negative feelings, and therefore higher LS. Self-direction was also expected to be positively related to LS, since it should promote efforts to manage and control one's own life - which should be more satisfactory than being led by others.

As for conformity, tradition, stimulation, achievement, power and safety, we had no clear predictions as to the direct impact of these val- 
ues on LS. It seems that LS should depend mainly on fulfilling these values, not on having them. For example, one can value power, but if one has no power over anything, this can hardly promote LS.

\section{Method}

\section{PARTICIPANTS AND PROCEDURE}

Two hundred and thirty-seven students of various departments (mainly economics, psychology, management, and journalism) of the Jagiellonian University in Kraków, Poland (120 women, 117 men) took part in the research. The mean age of the participants was 22.0 years $(S D=1.8$, range $19-30)$. Twenty participants were 19 years old $(8.4 \%)$; $212(89.4 \%)$ were $20-25$ years old; five $(2.2 \%)$ were between 26 and 30 years old. The data was collected by a trained interviewer, supervised by the first author of this paper. The interviewer recruited the subjects through contact with the departments' lecturers. The participants' anonimity was preserved.

The participants completed the measures described below in groups of 10 to 20 persons, in a supervised classroom setting. Participation was anonymous and voluntary, and no compensation was given for it.

\section{MEASURES}

The satisfaction with life scale (SWLS). This 5-item scale (Diener, Emmons, Larsen, \& Griffin, 1985) measures global cognitive judgments about life as a whole. The items are rated from 1 (strongly disagree) to 7 (strongly agree). Higher scores on the SWLS indicate greater satisfaction with one's life. The SWLS has demonstrated good validity in Poland (Juczyński, 2009). Cronbach's $\alpha$ for this measure, as well as for all the other ones used, are presented in Table 1.

The Zimbardo time perspective inventory (ZTPI). The original version of this inventory (Zimbardo \& Boyd, 1999) consists of 56 statements and identifies the five TPs described above. In the present research, a short version consisting of 15 items, adapted by Cybis, Rowiński, and Przepiórka (2012) was used. The items are rated from 1 (very untrue) to 5 (very true). The questionnaire has been found to have adequate psychometric properties in studies in more than 20 countries, including Poland (Przepiórka, 2011).

The portrait values questionnaire (PVQ). This 40-item inventory (Schwartz, 2005) identifies the aforementioned 10 basic values, defined in terms of theircentral goal. The items are rated on a scale from 1 (very much like me) to 6 (not like me at all). The PVQ has demonstrated validity in a Polish sample (Cieciuch \& Schwartz, 2012).

\section{STATISTICAL ANALYSES}

The hypotheses were tested by means of path analyses, using the lavaan software (Rosseel, 2012) for the $R$ Environment (R Core Team, 2016). Maximum-likelihood estimation was applied and cut-points for estimating the goodness of fit recommended by $\mathrm{Hu}$ and Bentler (1999) were adopted. The same software and criteria were used for the confirmatory factor analyses.

\section{RESULTS}

First, intercorrelations among all variables were calculated, together with their internal consistencies (Cronbach's $\alpha$ ), means and SDs. The results are presented in Table 1.

Cronbach's a for most variables was low, but it may be due to the scales being comprised of very few items: the ZTPI scales included three items per scale, the PVQ contained three to five items, and the SWLS had five items. Given this, the somewhat low as are not surprising. However, to additionally verify the validity of the scales, confirmatory factor analyses were carried out. For the ZTPI, the results indicated a poor fit: $\chi^{2}(80)=153.71, \mathrm{CFI}=.88, \mathrm{TLI}=.85, \mathrm{SRMR}=.07$, RMSEA $=.06[.05, .08]$. As for the PVQ, the analysis was only possible after removing the conformity subscale, otherwise the covariance matrix was not positively definite. Results indicated a very poor fit: $\chi^{2}(558)$ $=1304.35, \mathrm{CFI}=.73, \mathrm{TLI}=.69, \mathrm{SRMR}=.009, \mathrm{RMSEA}=.08[.07, .08]$. Therefore, caution is required when interpreting the following results.

There were four statistically significant, positive bivariate correlations between LS and the values of benevolence, stimulation, achievement, and power. Moreover, LS was significantly correlated with three of the five TPs: negatively with past negative and positively with past positive and future. The following relations between TPs and values were also present: past negative was positively correlated with conformity and universalism, Past positive was positively correlated with tradition, benevolence, stimulation, hedonism, and security; Present hedonistic was positively correlated with benevolence, universalism, self-direction, stimulation, hedonism, and achievement; Present fatalistic was positively correlated with hedonism and negatively with achievement. Finally, future was positively correlated with conformity, tradition, universalism, and security, and negatively with hedonism. All of these correlations were rather weak, ranging from $r=.13$ for past negative and universalism to $r=.35$ for present hedonistic and hedonism.

The main hypothesis stated that the relation between values and LS would be mediated by TPs. Such a mediational hypothesis is challenged by the fact that there were no significant correlations between values and LS. However, as Hayes stated (2013, p. 87), "lack of correlation does not disprove causation". Also, it is possible that correlations which are not significant in bivariate analyses may become significant in a multivariate approach due to suppression effects (e.g., Kline, 2016). Therefore, analyses pertaining to the main mediational hypotheses were performed via path analysis. Primarily, a model was fitted in which all values were predictors of all TPs, as well as of LS, and all TPs were predictors of LS.

The goodness of fit indices for the basic model were not impressive: $\chi^{2}(10, \mathrm{~N}=237)=24.52, p<.001, \mathrm{CFI}=.93, \mathrm{TLI}=.49, \mathrm{SRMR}=.02$, RMSEA $=.08[.04, .12]$. The poor fit was obviously due to many paths being statistically insignificant, as can be seen in Table 2 .

After removing insignificant paths and rerunning the model, the fit was acceptable: $\chi^{2}(41, \mathrm{~N}=237)=52.94, p=.10, \mathrm{CFI}=.95$, TLI $=.91$, SRMR $=.05, \mathrm{RMSEA}=.04[.01, .06]$. The path coefficients for the corrected model were nearly all significant, except for past negative versus universalism (see Table 3 ). The final model is graphically presented in Figure 1. 
TABLE 1.

Cronbach a, Means, SDs, and Intercorrelation of Values, Time Perspectives, and Life Satisfaction

\begin{tabular}{|c|c|c|c|c|c|c|c|c|c|c|c|c|c|c|c|c|c|c|}
\hline & 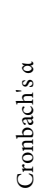 & $\sum_{\tilde{\Xi}}^{\infty}$ & ڤิ & $\begin{array}{l}\hat{\tilde{\Xi}} \\
\text { है } \\
\stackrel{0}{0} \\
0 \\
0\end{array}$ & 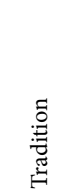 & 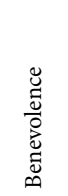 & 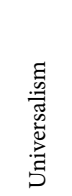 & 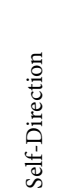 & 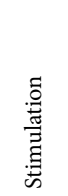 & 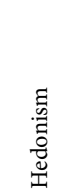 & 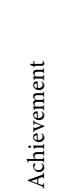 & $\begin{array}{l}\ddot{\tilde{J}} \\
\text { है }\end{array}$ & 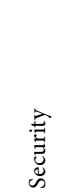 & 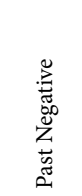 & 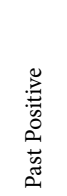 & 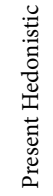 & 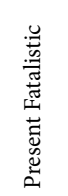 & 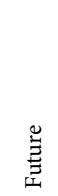 \\
\hline Conformity & .65 & 3.58 & .96 & & & & & & & & & & & & & & & \\
\hline Tradition & .57 & 3.14 & .97 & $.55^{* *}$ & & & & & & & & & & & & & & \\
\hline Benevolence & .63 & 4.39 & .79 & $.39^{* *}$ & $.31^{* *}$ & & & & & & & & & & & & & \\
\hline Universalism & .77 & 3.95 & .96 & $.31^{* *}$ & $.32^{* *}$ & $.43^{* *}$ & & & & & & & & & & & & \\
\hline Self-Direction & .57 & 4.68 & .80 & -.09 & $-.13^{*}$ & $.21^{* *}$ & $.22^{* *}$ & & & & & & & & & & & \\
\hline Stimulation & .62 & 3.81 & 1.03 & -.08 & -.10 & .10 & $.13^{*}$ & $.39^{* *}$ & & & & & & & & & & \\
\hline Hedonism & .80 & 3.67 & 1.11 & -.05 & $-.18^{* *}$ & .07 & .00 & $.23^{* *}$ & $.43^{* *}$ & & & & & & & & & \\
\hline Achievement & .83 & 4.21 & 1.09 & $.14^{*}$ & -.09 & $.14^{*}$ & .07 & $.45^{* *}$ & $.35^{* *}$ & $.31^{* *}$ & & & & & & & & \\
\hline Power & .72 & 3.22 & 1.15 & .03 & -.11 & -.06 & $-.13^{*}$ & $.31^{* *}$ & $.28^{* *}$ & $.29^{* *}$ & $.58^{* *}$ & & & & & & & \\
\hline Security & .54 & 3.76 & .88 & $.42^{* *}$ & $.42^{* *}$ & $.16^{*}$ & $.38^{* *}$ & .12 & -.02 & -.02 & $.29^{* *}$ & $.13^{*}$ & & & & & & \\
\hline Past Negative & .71 & 3.01 & .99 & $.19^{* *}$ & -.02 & .11 & $.13^{*}$ & -.04 & -.07 & .08 & .05 & -.01 & .02 & & & & & \\
\hline Past Positive & .48 & 3.34 & .80 & .04 & $.16^{*}$ & $.14^{*}$ & .05 & .07 & $.20^{* *}$ & $.16^{*}$ & .12 & .07 & $.17^{\star *}$ & $-.16^{*}$ & & & & \\
\hline Present Hedonistic & .44 & 3.92 & .69 & .00 & -.04 & $.20^{* *}$ & $.21^{* *}$ & $.24^{* *}$ & $.33^{* *}$ & $.35^{\star *}$ & $.21^{* *}$ & .06 & -.02 & .00 & $.27^{* *}$ & & & \\
\hline Present Fatalistic & .57 & 2.29 & .87 & .06 & .09 & .02 & .04 & -.10 & -.01 & $.21^{\star \star}$ & $-.16^{*}$ & -.08 & .03 & .10 & .01 & .11 & & \\
\hline Future & .76 & 3.26 & .98 & $.18^{* *}$ & $.20^{* *}$ & .12 & $.22^{* *}$ & .08 & -.09 & $-.19^{* *}$ & .08 & .02 & $.32^{\star *}$ & -.07 & .04 & .00 & -.06 & \\
\hline Life Satisfaction & .78 & 4.17 & 1.05 & .06 & .10 & $.16^{*}$ & .01 & .11 & $.13^{*}$ & .01 & $.14^{*}$ & $.15^{*}$ & .04 & $-.39^{\star *}$ & $.20^{* *}$ & .06 & -.01 & $.24^{* *}$ \\
\hline
\end{tabular}

Note. Correlations among life satisfaction, time perspectives, and values are marked in bold. Correlations among all time perspectives, and among values are marked in italics.

${ }^{*} p<.05,{ }^{* *} p<.01$.

As can be seen in Figure 1, in the final model, LS was predicted positively and directly by benevolence, and indirectly by conformity and tradition via past negative, the latter one being a negative predictor. LS was also predicted indirectly by hedonism and security via future - hedonism was a negative, and security a positive predictor of future, which in turn was a positive predictor of LS. Apart from this, past positive was predicted positively by tradition, stimulation and security; present hedonistic - positively by universalism, stimulation and hedonism; present fatalistic - positively by hedonism and negatively by achievement.

\section{DISCUSSION}

The main aim of the present research was to analyze the relationships between values, TPs, and cognitive aspects of SWB (i.e., LS). The main hypothesis stated that values predict LS both directly and indirectly through time perspective. The detailed hypotheses described in the Introduction section were only partially confirmed. In general, this result is in line with existing empirical data.

In accordance with the research mentioned in the Introduction section (not many direct relationships between values and LS were found and the results considering this relationship are inconsistent), only one value predicted LS directly and positively - benevolence. The positive relationship of benevolence with LS was also found in other studies (Jarden, 2010; Kasser \& Ryan, 1993). Sagiv and Schwartz (2000) referred to benevolence as "healthy value." It also related to growth needs which are more strongly associated with SWB (Bilsky \& Schwartz, 1994). Benevolence as a value involves caring for significant others,. loyalty, responsibility, friendship, and mature love.
Lyubomirsky (2008) includes sustaining relationships on the list of the most important strategies for increasing happiness. For Seligman (2011), positive relationships are one of the five core elements of psychological well-being and happiness, and cultivating relationships with others is one of the foundations on which SWB is built. It is believed that doing someone a favor without wanting anything in return is one of the most reliable ways to improve one's well-being. The obtained result, which shows a direct relationship between benevolence and LS, supports these findings. It can be assumed that preference for this value goes hand in hand with caring more about positive relationships with loved ones, which increases LS.

The most important results of the present study concern the indirect relationship of values with LS through TPs. To test this hypothesis, we performed path analyses. Four values were revealed to influence LS through TPs: conformity, tradition, security, and hedonism. Two of those values (conformity and tradition) influenced LS through the past negative, and two others (security and hedonism) through the future TP.

\section{Past Orientation as a Mediator Between Values and Life Satisfaction}

It turned out that conformity was positively related to the past negative TP, but tradition was related negatively, which negatively predicted LS. Zimbardo and Boyd (2008) posit that past negative or past positive TP concern more an attitude towards the past rather than an objective record of good or bad events and the results of our actions. Negative or positive past TP is not objective an illustration of the past. Memories change with time and are like constructions which are influenced by 


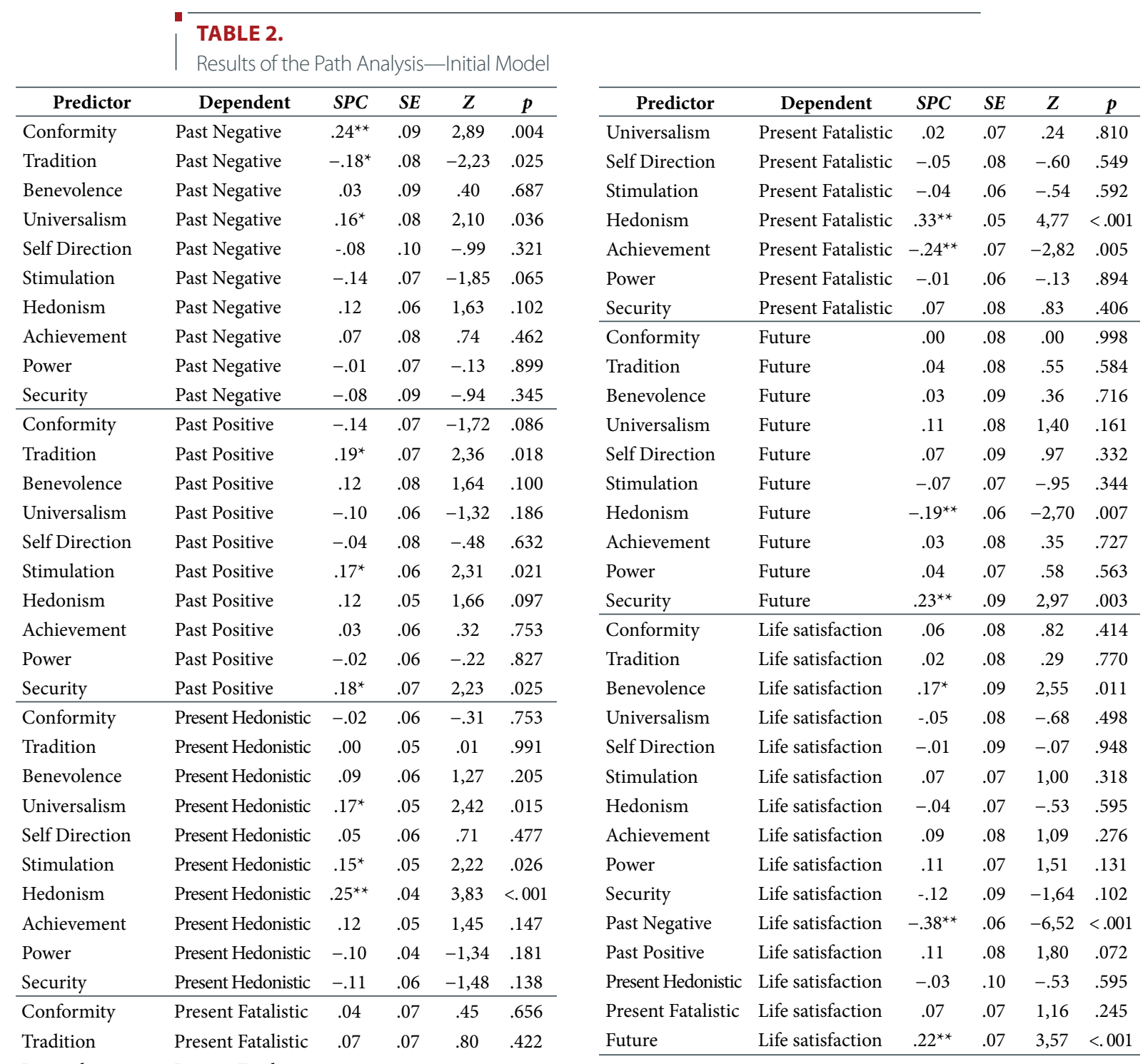

Note. $\mathrm{SPC}=$ standardized path coefficients; $\mathrm{SE}=$ standard errors.$$
{ }^{*} p<.05,{ }^{* *} p<.01 \text {. }
$$

\section{TABLE 3.}

Results of the Path Analysis-Corrected Model

\begin{tabular}{llcccc}
\hline \multicolumn{1}{c}{ Predictor } & \multicolumn{1}{c}{ Dependent } & \multicolumn{1}{c}{$\boldsymbol{S P C}$} & $\boldsymbol{S E}$ & $\boldsymbol{Z}$ & $\boldsymbol{p}$ \\
\hline Conformity & Past Negative & $.27^{* *}$ & .08 & 3.50 & \multicolumn{1}{c}{$<$} \\
& & & & & .001 \\
Tradition & Past Negative & $-.21^{* *}$ & .08 & -2.72 & .006 \\
Universalism & Past Negative & .12 & .07 & 1.72 & .085 \\
Tradition & Past Positive & $.13^{*}$ & .06 & 2.01 & .045 \\
Stimulation & Past Positive & $.20^{* *}$ & .05 & 3.22 & .001 \\
Security & Past Positive & $.15^{*}$ & .06 & 2.30 & .021 \\
Universalism & Present Hedonistic & $.20^{* *}$ & .04 & 3.46 & .001 \\
Stimulation & Present Hedonistic & $.21^{* *}$ & .04 & 3.19 & .001 \\
\hline
\end{tabular}

\begin{tabular}{llcccc}
\hline \multicolumn{1}{c}{ Predictor } & \multicolumn{1}{c}{ Dependent } & \multicolumn{1}{c}{$\boldsymbol{S P C}$} & $\boldsymbol{S E}$ & $\boldsymbol{Z}$ & $\boldsymbol{p}$ \\
\hline Hedonism & Present & $.24^{* *}$ & .04 & 3.80 & $<.001$ \\
& Hedonistic & & & & \\
Hedonism & Present Fatalistic & $.29^{* *}$ & .05 & 4.54 & $<.001$ \\
Achievement & Present Fatalistic & $-.27^{* *}$ & .05 & -4.12 & $<.001$ \\
Hedonism & Future & $-.18^{* *}$ & .05 & -2.97 & .003 \\
Security & Future & $.32^{* *}$ & .07 & 5.20 & $<.001$ \\
Benevolence & Life satisfaction & $.18^{* *}$ & .08 & 3.15 & .002 \\
Past Negative & Life satisfaction & $-.39^{* *}$ & .06 & -6.74 & $<.001$ \\
Future & Life satisfaction & $.19^{* *}$ & .06 & 3.36 & .001 \\
\hline
\end{tabular}




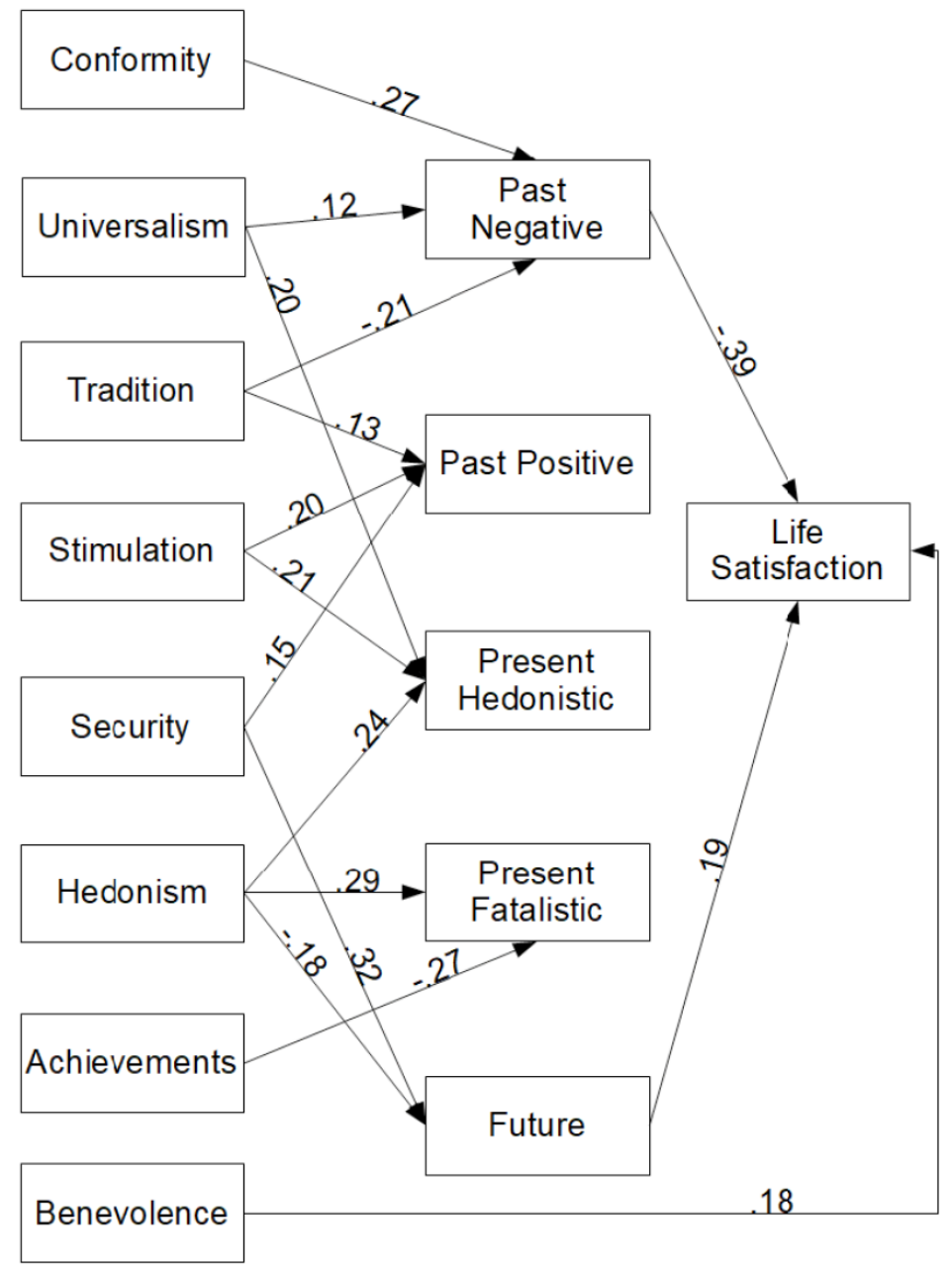

FIGURE 1.

Graphical representation of the final model of the path analysis.

current attitudes, beliefs, and available information. For example, the present mood affects the memory of the past. A higher score of any given person on the past negative scale does not mean that this person's past is objectively worse and that they had more negative experiences than a person who scored significantly lower on that scale. The objective past influences all of us, but it does not completely determine who we are; as noted by Zimbardo and Boyd (2008), our attitudes towards past events and their interpretation is more important than the events themselves.

Numerous studies show that people who scored high on the negative past scale were significantly less happy and less satisfied with life than people who scored low. Meanwhile, people who scored high on the positive past scale were happier and more satisfied with life than those who scored low (see Zimbardo \& Boyd, 2008; Drake et al., 2008). The results of the conducted path analysis show that tradition values are not a direct predictor of LS. However, they can influence LS through TP. Preference for tradition (respect, commitment, and acceptance of the customs and ideas provided by culture or religion) decreased negative thinking about the past, which had a negative influence on LS in the studied group. At the same time, tradition is a positive predictor of a past positive $\mathrm{TP}$.

Again, tradition as a value means acceptance, respect, and keeping the customs of one's culture and family. This value is related to a generally positive attitude towards the past because to the extent to which people share positive visions of the past, they try to maintain a cultural or customary status quo. This is supported by studies showing that people involved in past family traditions had a higher past positive TP than those who were not (Zimbardo \& Boyd, 2008). Thus, we assumed that the value of tradition can be positively linked to the past positive and negatively linked to the past negative TP.

\section{Future Orientation as a Mediator Between Values and LS}

Results of numerous studies showed a positive relationship between the future TP and LS (Cunningham et al., 2015). The future, just like the past, is not experienced directly. It is a psychologically constructed state of mind (Zimbardo \& Boyd, 2008).

The results of our studies show that two values (security and hedonism) influenced LS through the future TP. Hedonism was 
negatively related to future, which, in turn, positively predicted LS. The future TP, as defined by Zimbardo and Boyd (1999), refers to planning, meeting deadlines, endurance, striving for long-term goals, and an orientation towards success. The future TP is linked to discipline, perseverance, punctuality, and delaying gratification (unlike focusing on the hedonistic present). As such, hedonism which means pleasure, self-indulgence, sensuous self-gratification, and enjoying life may limit the future TP, in which a strong orientation towards goals and achieving success are the key. However, hedonism clearly and positively influences the present hedonistic TP.

The second value that influenced LS through future was security. Preference for security positively predicted the future TP. Schwartz (2012) defines this value's goal as "safety, harmony, and stability of society, of relationships, and of self. Security values derive from basic individual and group requirements" (p. 6). It can be assumed that the future TP (understood as taking into consideration the future consequences of one's actions and decisions) may result from security. Previous studies showed that security is important to people who scored high on the future scale; they avoid acting dangerously, for example, they rarely drive in a risky way, rarely drive under the influence of alcohol, or have unprotected sex. Those people are less prone to addictions, such as gambling, alcohol, or drugs (see Rothspan \& Read, 1996; Alvos, Gregson, \& Ross, 1997).

Interestingly, in two cases, the impact of values on LS, mediated by TPs, resulted in lowering LS when the results on the predictors were high: Conformity was positively related to past negative, which negatively predicted LS. Hedonism was negatively related to future, which was positively related to LS. In these cases, higher results on a predictor resulted in lower values of LS. In one case, higher values indirectly increased LS; higher security increased future, which was positively related to LS. Additionally, tradition decreased negative thinking about the past, which had a negative relationship with LS.

Zimbardo and Boyd (1999) assume that TPs are learned, and what follows, can be modified. Having an extreme TP (when one TP dominates) limits our experiences and abilities to achieve goals. The authors suggest taking on a balanced and flexible perspective. According to them, an optimal TP profile consists of a high level of past positive, moderately high levels of present hedonistic and future, and low levels of present negative and present fatalistic. At the same time, they emphasize the importance of a flexibility of choice of a particular perspective depending on the requirements of the situation. When implementing a project-the future TP should dominate; when we want to enjoy our vacation - it is a good idea to concentrate on living in the moment (present hedonistic), and, for example, during holidays with family, it is important to focus on family traditions (past positive).

The authors give various practical techniques to manage TPs. Numerous strategies described by Lyubomirsky (2008), which an also increase SWB, are based on the possibility to flexibly use TPs. We assume that TP regulation can increase LS in the context of individual value profiles. Based on our research, we can hypothesize that for some values, regulation or a change of some TPs can have a positive influence on LS. For example, for people who prefer the the conserva- tive values group, such as tradition and conformity, it is particularly important to modify past perspectives; with the emphasis on weakening past negative and emphasizing past positive. For those with a high preference for conformity, it is particularly important to work on the attitudes towards the past, especially past positive. In the case of preferring security, a good strategy would be to develop past positive and future TPs. Since Security is positively linked to those TPs, and these have a positive relationship with SWB, according to our and numerous other studies.

In the Introduction section, we pointed out the inconsistency of results concerning the relationship between values and SWB, which may come from a number of factors. LS depends not only on one's values profile, but also on the possibility of fulfilling those values (LS may be lower when the need to fulfill one's values is frustrated). Cultural differences and the studied country's socio-economic development can moderate the relationship between values and LS. The association between values and SWB can also be mediated by various factors, for example, TPs. Our research has shown that there is an indirect influence of some values on LS via TPs.

\section{Practical Implications}

The immediate practical implications of the present basic study are not apparent. However, the results clearly show that some values may influence LS, directly as well as indirectly via TPs. Given the fact TPs are shaped by socio-cultural conditions, this knowledge provides a basis for increasing LS indicators on the personal and social level by means of TP modulation. This may be done by education or other kinds of intervention. However, detailed transformation of the present results into applicable tools remains a task for future research.

\section{Study Limitations}

As the present study was correlational in design, any conclusions regarding causal relations must be drawn cautiously. There is no way to rule out the possibility that, for example, TPs foster values which, in turn, facilitate LS. However, we did our best to justify our model.

Most relationships found in the present study were rather small; they were statistically significant because of the relatively large sample. Also, most measure subscales had somewhat limited reliability. It is therefore possible that the real magnitude of the described correlations is higher, and is only low in the present research because of the attenuation effects. Finally, the generalizability of the present results is limited, as the research was conducted on Polish students only. It is known that there are cross-cultural differences in value priorities (Schwartz, 1994) as well as TPs (Sircova et al., 2015). We also have some preliminary data concerning similar hypotheses gathered in a different country (Mexico). The results were not the same as the present ones, although some mediations were found in Mexico as well.

Unfortunately, the reliability of the subscales of both ZTPI and PVQ was poor, as was their fit in light of the confirmatory factor analyses. This may have contributed to the fact that most of the observed relations were rather weak. Caution is advised for future research using these questionnaires. 


\section{REFERENCES}

Alvos, L., Gregson, R. A., \& Ross, M. W. (1997). Future time perspectives in current and previous injecting drugs users. Drug and Alcohol Dependence, 31, 193-197. doi: 10.1016/0376-8716(93)90072-X Wلس Anagnostopoulos, F., \& Griva F. (2012). Exploring time perspective in Greek young adults: Validation of the Zimbardo Time Perspective Inventory and relationships with mental health indicators. Social Indicators Research, 106, 41-59. doi: 10.1007/

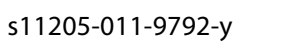

Bilsky, W., \& Schwartz, S. H. (1994). Values and personality. European

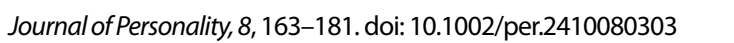

Boniwell, I. (2005). Beyond time management: how the latest research on time perspective and perceived time use can assist clients with time-related concerns. International Journal of

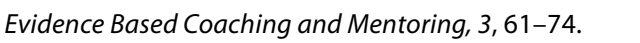

Boniwell, I., Osin, E., Linley, A. P., \& Ivanchenko, G. V. (2010). A question of balance: time perspective and well-being in British and Russian samples. The Journal of Positive Psychology, 5, 24-40. doi: 10.1080/1743976090327118 سلس سلس

Boniwell, I., Osin, E. \& Sircova, A. (2014). Introducing time perspective coaching: A new approach to improve time management and enhance well-being. International Journal of Evidence Based Coaching and Mentoring, 12, 24-40. الس الس الس

Bryant, F. B. (2003). Savoring beliefs inventory (SBI): A scale for measuring beliefs about savoring. Journal of Mental Health, 12, 175-196. doi: 10.1080/0963823031000103489 السلسلسلس

Cantor, N., \& Zirkel, S. (1990). Personality, cognition, and purposive behavior. In: L. A. Pervin (Ed.), Handbook of personality; Theory and research (pp. 135-164). New York, NY: Guilford.

Carstensen L. L., Isaacowitz, D. M., \& Charles, S. T. (1999). Taking time seriously: A theory of socioemotional selectivity. American Psychologist, 54, 165-181. doi: 10.1037/0003-066X.54.3.165 الفالسلسلا

Cieciuch, J., \& Schwartz, S. (2012). The number of distinct basing values and their structure assessed by PVQ40. Journal of Personality Assessment, 94, 321-328. doi:

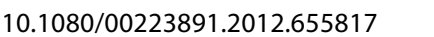

Cunningham, K. F., Zhang, J. W., \& Howell, R. T. (2015). Time perspectives and subjective well-being: A dual-pathway framework. In M. Stolarski, N. Fieulaine, \& W. van Beek (Eds.), Time perspective theory, review, research, and application (pp. 403415). Cham, Switzerland: Springer International Publishing.

Cybis, N., Rowiński, T., \& Przepiórka, A. (2012, September). Development of the Polish version of Zimbardo Time Perspective Inventory. Paper presented at Ist International Conference on Time Perspective, Coimbra, Portugal.

Diener, E., \& Biswas-Diener, R. (2008). Happiness: Unlocking the mysteries of psychological wealth. Malden, MA: Blackwell Publishing.

Diener, E., Emmons, R., Larsen, R. J., \& Griffin, S. (1985). The satisfaction with life scale. Journal of Personality Assessment, 49, 71-75. doi: 10.1207/s15327752jpa4901_13 الس الس الس

Drake, L., Duncan, E., Sutherland, F., Abernethy, C., \& Henry, C. (2008). Time perspective and correlates of well-being. Time and Society, 17, 47-61. doi: 10.1177/0961463X07086304 س山ل|

Dunkel, C. S., \& Weber, J. L. (2010). Using three levels of personality to predict time perspective. Current Psychology, 29, 95-103. doi: 10.1007/s12144-010-9074-x الس السلسل

Durayappah, A. (2010). The 3P Model: A general theory of subjective well-being. Journal of Happiness Studies, 12, 681-716. doi:

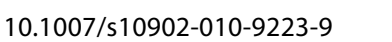

Dwivedi, A., \& Rastogi, R. (2017). Future time perspective, hope and life satisfaction: A study on emerging adulthood. Jindal Journal of Business Research, 5, 17-25. doi:

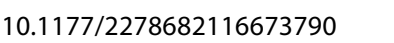

Fortunato, V. J., \& Furey, J. T. (2009). The Theory of Mind Time and the relationships between thinking perspective and the Big Five personality traits. Personality and Individual Differences, 47, 241-246. doi: 10.1016/j.paid.2009.03.006 السلسلس

Haslam, N., Whelan, J., \& Bastian, B. (2009). Big Five traits mediate associations between values and subjective well-being. Personality and Individual Differences, 46, 40-42. doi: 10.1016/j. paid.2008.09.001 إلسلس

Hayes, A. F. (2013). Introduction to mediation, moderation, and conditional process analysis. A regression-based approach. New York, NY:The Guilford Press. Hu, L., \& Bentler, P. M. (1999). Cutoff criteria for fit indexes in covariance structure analysis: Conventional criteria versus new alternatives. Structural Equation Modeling, 6, 1-55. doi:

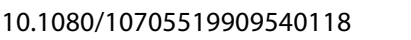

Jarden, A. (2010). Relationships between personal values, and depressed mood and subjective wellbeing. Thesis submitted for the degree of Doctor of Philosophy. University of Canterbury, Christchurch.

Juczyński, Z. (2009). Narzędzia pomiaru w promocji psychologii zdrowia [Measurement tools in promoting health psychology]. Warsaw, Poland: Pracownia Testów Psychologicznych Polskiego Towarzystwa Psychologicznego.

Kairys, A., \& Liniauskaite, A. (2015). Time perspective and personality. In: M. Stolarski, N. Fieulane \&W. van Beek (Eds.). Time perspectives, theory, review, research, and application (pp. 99-113). New York, NY: Springer.

Kasser, T. M., \& Ryan, R. M. (1993). A dark side of the American dream: Correlates of financial success as a central life aspiration. Journal of Personality and Social Psychology, 65, 410-422. doi: 10.1037/0022-3514.65.2.410 إلسلس

Kim-Prieto, C., Diener, E., Tamir, M., Scollon, C., \& Diener, M. (2005). Integrating the diverse definitions of happiness: A time sequential framework of subjective well-being. Journal of Happiness Studies, 6, 261-300. doi: 10.1007/s10902-005-7226-8 الفالس الس الس Kline, R. B. (2016). Principles and practice of structural equation modeling. New York, NY: The Guillford Press.

Lu, M., Li, A.Y., Fung, H. H., Rothermund, K., \& Lang, F. R. (2018). Different future time perspectives interplay in predicting life satisfaction. GeroPsych: The Journal of Gerontopsychology and Geriatric Psychiatry, 31, 103-113. doi: 10.1024/1662-9647/a000192 السلسلس

Lyubomirsky, S. (2008). The how of happiness: A scientific approach to getting the life you want. New York, NY: Penguin Press. 
Mello, Z. R., \& Worrell, F. C. (2015). The past, the present, and the future: A conceptual model of time perspective in adolescence. In: M. Stolarski, N. Fieulane, \& W. van Beek (Eds.), Time perspectives, theory, review, research, and application (pp. 115-129). New York, NY: Springer.

Milfont, T. L, \& Gouveia, V.V. (2006). Time perspective and values: An exploratory study of their relations to environmental attitudes. Environmental Psychology, 26, 72-82. doi: 10.1016/j.jenvp.2006.03.001 الم الملسلس

Özdemir, A. (2014). The relationship between value domains and subjective well-being of employees: Evidence from Turkey. International Journal of Human Resource Studies, 4, 148-166. doi: 10.5296/ ijhrs.v4i4.6384 السلسلس

Pavot, W., Diener, E., \& Suh, E. (1998). The temporal satisfaction with life scale. Journal of Personality Assessment, 70, 340-354. doi: 10.1207/s15327752jpa7002_11 السلسلسلس

Przepiórka, A. (2011). The determinants of realizing entrepreneurial goals. Unpublished doctoral thesis. The John Paul II Catholic University of Lublin, Poland.

$\mathrm{R}$ Core Team (2016). R: A language and environment for statistical computing. R Foundation of Statistical Computing, Vienna, Austria. Retrieved from https://www.R-project.org/

Roccas, S., Sagiv, L., Schwartz, S. H., \& Knafo, A. (2002). The Big Five personality factors and personal values. Personality and Social Psychology Bulletin, 28, 789-801. doi: 10.1177/0146167202289008 1لس

Rosseel, Y. (2012). lavaan: An R package for structural equation modeling. Journal of Statistical Software, 48, 1-36. Retrieved from https://users.ugent.be/ yrosseel/lavaan/lavaanIntroduction.pdf

Rothspan, S., \& Read, S. J. (1996). Present versus future time perspectives and HIV risk among heterosexual college students. Health Psychology, 15, 131-134. السلسلسل

Sagiv, L., \& Schwartz, S. (2000). Value priorities and subjective wellbeing: direct relations and congruity effects. European Journal of Social Psychology, 30, 177-198. doi: 10.1002/(SICI)1099-

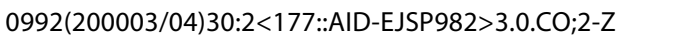

Sagiv, L., Roccas, S., \& Hazan, O. (2004). Value pathways to wellbeing: Healthy values, valued goal attainment, and environmental congruence. In A. Linley, \& J. Stephen (Eds.), Positive psychology in practice (pp. 68-85). New York, NY: John Wiley.

Schwartz, S. H. (1994). Are there universal aspects in the structure and contents of human values? Journal of Social Issues, 50, 19-45. doi: 10.1111/j.1540-4560.1994.tb01196.x Wلس الس

Schwartz, S. H. (2005). A proposal for measuring value orientations across nations. Questionnaire Package of the European Social Survey (pp. 259-290). Retrieved from https://pdfs. semanticscholar.org/376a/d809f1313cb41dfcffa8bd180949c273f8c2.pdf

Schwartz, S. H. (2006). Basic human values: Theory, measurement, and applications. Revue Française de Sociologie, 47, 929-968. السلسلسل

Schwartz, S. H. (2012). An overview of the Schwartz theory of basic values. Online Readings in Psychology and Culture, 2, 1-20. doi: 10.9707/2307-0919.1116 الس الس
Seligman, M. (2011). Flourish. A visionary new understanding of happiness and well-being. New York, NY: Free Press.

Sircova, A., van de Vijver, F. J. R., Osin, E., Milfont, T. L., Fieulaine, N., Kislali-Erginbilgic, A., \& Zimbardo, P. G. (2015). Time perspective profiles of cultures. In M. Stolarski, N. Fieulaine, \& W. van Beek (Eds.), Time perspective theory; Review, research, and application (pp. 169-187). Cham, Switzerland: Springer International Publishing.

Sobol-Kwapinska, M. (2016). Calm down - It's only neuroticism. Time perspectives as moderators and mediators of the relationship between neuroticism and well-being. Personality and Individual Differences, 94, 64-71. doi: 10.1016/j. paid.2016.01.004

Sortheix, F. M., \& Lönnqvist, J.-E. (2014). Personal value priorities and life satisfaction: The role of socio-economic development across Europe. Journal of Cross-Cultural Psychology, 45,

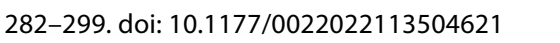

Stolarski, M., \& Matthews, G. (2016). Time perspectives predict mood states and satisfaction with life over and above personality. Current Psychology, 35, 516-526. doi: 10.1007/s12144-016-9515-2 السلبلسلس

Stolarski, M., Vowinckel, J., Jankowski, K. S., \& Zajenkowski, M. (2016). Mind the balance, be contented: Balanced time perspective mediates the relationship between mindfulness and life satisfaction. Personality and Individual Differences, 93, 27-31. doi: 10.1016/j.paid.2015.09.039 Шلسلس

Sword, R. M., Sword, R. K., Brunskill, S. R., \& Zimbardo, P. $G$ (2014). Time Perspective therapy: A new time-based metaphor therapy for PTSD. Journal of Loss and Trauma: International Perspectives on Stress \& Coping, 19, 197-201. doi: 10.1080/15325024.2013.763632

Tayli, A. (2015). Life values associated with life satisfaction in the Turkish university sample. Anthropologist, 21, 323-329. doi: 10.1080/09720073.2015.11891821 سلس

Uzefovsky, F., Döring, A. K., \& Knafo-Noam, A. (2016). Values in middle childhood: Social and genetic contributions. Social Development, 25, 482-502. doi: 10.1111/sode. 12155 (لسلسل

Zhang, J. W., \& Howell, R. T. (2011). Do time perspectives predict unique variance in life satisfaction beyond personality traits? Personality and Individual Differences, 50, 1261-1266. doi: 10.1016/j.paid.2011.02.021

Zhang, J. W., Howell, R. T., \& Stolarski, M. (2013). Comparing three methods to measure a balanced time perspective: The relationship between balanced time perspective and subjective well-being. Journal of Happiness Studies, 14, 169-184. doi: 10.1007/s10902-012-9322-x سلب

Zimbardo, P. G., \& Boyd, J. N. (1999). Putting time in perspective: A valid, reliable individual-differences metric. Journal of Personality and Social Psychology, 77, 1271-1288. doi: 10.1007/978-3-319-07368-2_2 السلسلسلس

Zimbardo, P. G., \& Boyd, J. N. (2008). The time paradox. New York, NY: Free Press.

RECEIVED 04.08.2018| ACCEPTED 24.04.2019 